
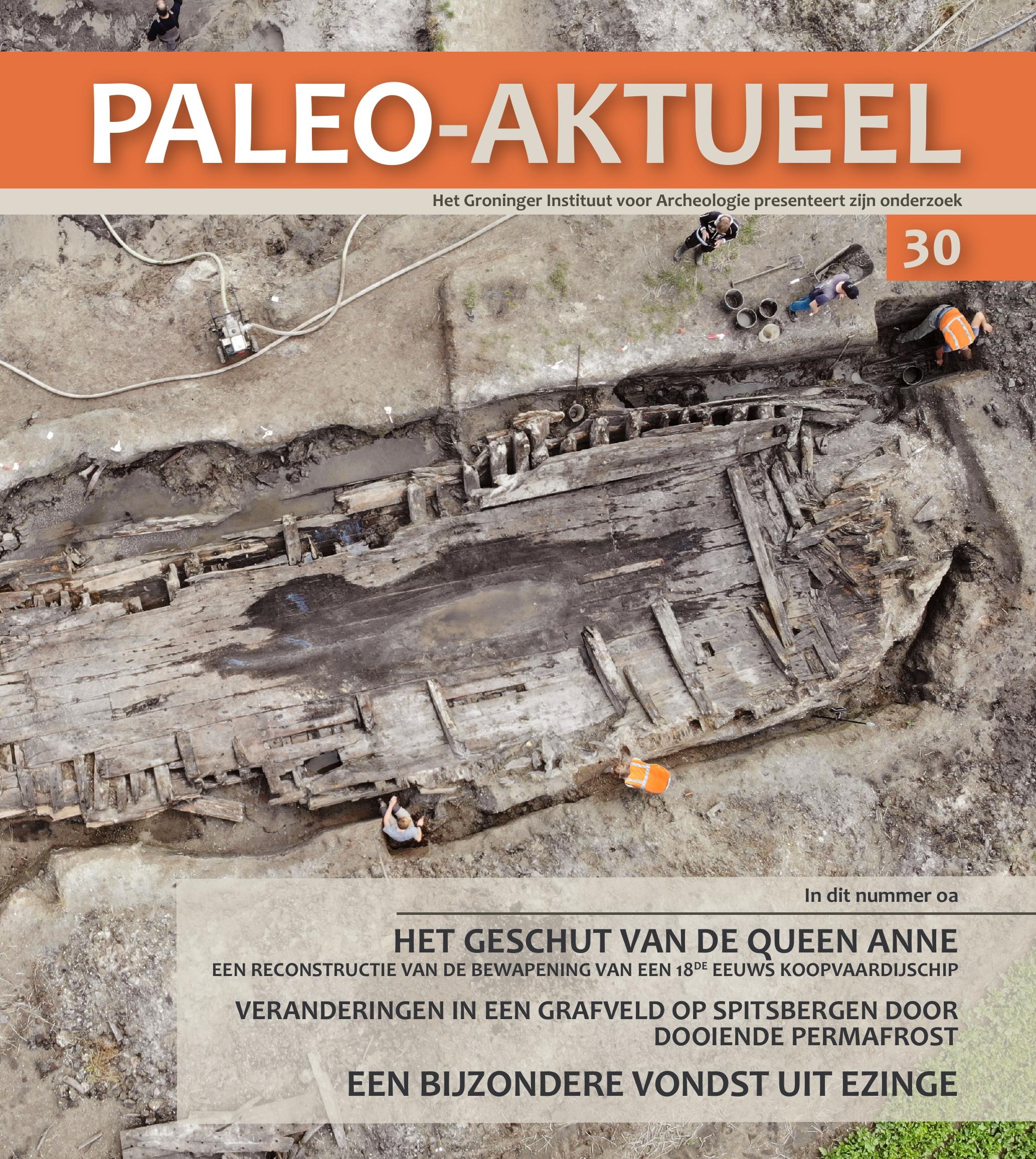
Met de jaarlijkse uitgave van Paleo-aktueel geven de medewerkers en studenten van het Groninger Instituut voor Archeologie inzicht in een deel van het lopende onderzoek van het instituut.

Aan dit nummer werkten mee: Stijn Arnoldussen, Sabrina Corbellini, Tamara Dijkstra, Henny Groenendijk, Hans Huisman, Lidewijde de Jong, Martijn van Leusen, Johan Nicolay, Annet Nieuwhof, Bert Nijboer, Daan Raemaekers, Iris Rom \& Mans Schepers.

Redactie: Flip Kramer (coördinatie), Elisabeth van 't Lindenhout \& Daan Raemaekers Vormgeving en omslagontwerp: Siebe Boersma

Correctie Engelse samenvattingen: Suzanne Needs-Howarth

Foto omslag: Dronebeeld van de omgevallen stuurboordzijde van de Queen Anne (scheepswrak NK 47-II). Foto Yftinus van Popta. Zie artikel van Popta \& Han Vastenhoud.

ISBN 9789492444981

ISSN 1572-6622

Website: www.paleo-aktueel.nl

Adres van de redactie

Rijksuniversiteit Groningen

Groninger Instituut voor Archeologie (GIA)

Poststraat 69712 ER Groningen

Tel.: 0503636712

gia@rug.nl

Adres van de uitgever

Barkhuis Publishing

Kooiweg 389761 GL Eelde

Tel. 0503080936 fax 0503080934

info@barkhuis.nl www.barkhuis.nl

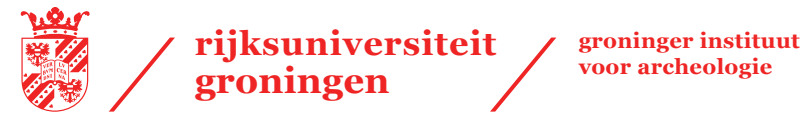

(c) GIA. Inlichtingen:

www.rug.nl/let/onderzoek/onderzoekinstituten/gia/publications 


\section{Paleo-aktueel 30}

Rijksuniversiteit Groningen / Groninger Instituut voor Archeologie (GIA)

University of Groningen / Groningen Institute of Archaeology

\& Barkhuis Publishing

Groningen, 2019 



\section{Inhoud}

'HIER WIL IK NOG NIET DOOD GEVONDEN WORDEN'. BESPIEGELINGEN OVER DE ABSENTIE VAN GRAVEN

Iris Rom \& Karla de Roest

BOUWEN AAN JEZELF DOOR TE BOUWEN VOOR EEN ANDER. EEN ARCHITECTURALE ANALYSE VAN DE GRAVEN UIT DE NOORDELIJKE BEGRAAFPLAATS VAN AYIOS VASILIOS Youp van den Beld

MALLIGHEDEN. EEN NOORD-FRANSE GIETMAL IN EEN NEDERLANDS MUSEUM

Hannie Steegstra

LA TORRETTA DELLA BUFALOTTA: STILLE GETUIGE VAN EEN VERDWENEN LANDSCHAP Remco Bronkhorst \& Jorn Seubers

GEBRUIKSAANWIJZING NIET INBEGREPEN?ARCHEOHOTSPOTS OPZETTEN IN DE PROVINCIE OVERIJSSEL

Anne Ponten

SCHOP, SPADE OF STUURRIEM? EEN BIJZONDERE VONDST UIT EZINGE

Annet Nieuwhof \& Reinder Reinders

DE VENDELHELM UIT HALLUM: WAT DOET DEZE HELM IN FRIESLAND?

Johan Nicolay

MAKEN EN HANDELEN: MEROVINGISCHE KRALEN UIT HET SITTARD-KEMPERKOUL GRAFVELD GEANALYSEERD

Hans Huisman, Marion Aarts, Mirjam Kars, Fardau Mulder, Dominique Ngan-Tillard \& Bertil van Os

'VAN KOPER BLIJF JE PROPER, VAN IJZER WORDT JE NIETS WIJZER': KLOOSTER YESSE, METAALVONDSTEN UIT 2017 EN 2018

Janne van Boldrik \& Berna van Wijk

VAN BOERDERIJ NAAR KLOOSTER NAAR WEESHUIS. DE GEBRUIKSPLANTEN OP HET TERREIN VAN DE ROODE WEESHUISSTRAAT, GRONINGEN

Morvenna van Rijn \& Frits Vrede

APPELS MET (KWEE)PEREN VERGELIJKEN

Chantal Assië \& Merit Hondelink 
WAT DOET DIE BRONZEN POT DAAR BIJ DE KEI VAN TIJNJE (FR.)?

Vincent van Vilsteren

HET GESCHUT VAN DE QUEEN ANNE. EEN RECONSTRUCTIE VAN DE BEWAPENING VAN HET ENGELSE KOOPVAARDIJSCHIP DAT IN DE $18^{\text {DE }}$ EEUW VOOR DE KUST VAN KUINRE VERGING Yftinus van Popta \& Han Vastenhoud

VERANDERINGEN IN EEN 17 ${ }^{\text {DE}}$-EEUWS GRAFVELD OP SPITSBERGEN DOOR DOOIENDE PERMAFROST

Maarten Loonen, Femke Bosscher, Han Vastenhoud, Lotte Zanting, Rosanne van Bodegom,

Frits Steenhuisen, Sarah Dresscher, Wouter Rooke \& Koos de Vries

DAT MAG IN DE KRANT! ARCHEOHISTORISCH ONDERZOEK NAAR DE ONDERGANG VAN EEN 19DE-EEUWSE TJALK OP DE ZUIDERZEE

Yftinus van Popta

WOODAN, DÉ DATABASE VOOR ARCHEOLOGISCH HOUT

Stephan Nicolaij \& Jelte van der Laan 


\title{
Maken en handelen: Merovingische kralen uit het Sittard-Kemperkoul grafveld geanalyseerd
}

\author{
Hans Huisman ${ }^{1,2}$, Marion Aarts 3 , Mirjam Kars ${ }^{4}$, Fardau Mulder ${ }^{2}$, \\ Dominique Ngan-Tillard ${ }^{5}$ \& Bertil van $\mathrm{Os}^{1}$
}

In september 2018 werd de nieuwe permanente tentoonstelling van Erfgoedcentrum De Domijnen in de gemeente Sittard-Geleen geopend. De opstelling is ingericht rond 24 topstukken. Eén hiervan bestaat uit de vier kralensnoeren die in 1982 werden gevonden in graf 11 van het Merovingische grafveld van Sittard-Kemperkoul. Bij de voorbereiding van de tentoonstelling kwam de vraag naar voren of moderne analysetechnieken die in de jaren 1980 nog niet beschikbaar waren meer informatie over deze kralen zouden kunnen opleveren. Chemische analyses en microCT-scans van laatprehistorische, Romeinse en vroegmiddeleeuwse kralen uit graven elders in Nederland hebben in de laatste jaren namelijk een reeks aan nieuwe inzichten opgeleverd over de herkomst van grondstoffen voor de productie van glas en de ambachtelijke vervaardiging van kralen. Het natuurwetenschappelijke onderzoek kan de vraag beantwoorden of de kralen in één of meerdere partijen zijn geproduceerd. Tot slot is de variatie in de samenstelling en de vorm van de kralen mogelijk een aanwijzing voor de aard en de reikwijdte van de contacten van de overledene en haar naasten.

\section{Kemperkoul-graf 11}

Het vroegmiddeleeuwse grafveld van Sittard werd in 1982 tijdens bouwwerkzaamheden ten behoeve van het uitbreidingsplan 'Kemperkoul' ten oosten van het toenmalige Sittard ontdekt (Zoetbrood 1984). Opgravingen maakten duidelijk dat het uit 88 graven bestond. Het merendeel van de graven bevatte grafobjecten die kenmerkend zijn voor de Merovingische periode: kralen, vaatwerk, gordels en wapens. Opmerkelijk is dat de meeste graven uit een houten kist of kamer bestonden. Deze zijn volledig vergaan, maar de contouren ervan konden nog wel als verkleuringen in de ondergrond opgetekend worden. Door de kalkarme samenstelling van de bodem zijn ook de skeletten vrijwel helemaal vergaan. In een enkel geval was nog een lijksilhouet te herkennen (Kars et al. 2016).

In het midden van het grafveld werd een graf aangetroffen (graf 11) dat oorspronkelijk bestond uit een houten kist die op twee houten balken was geplaatst (fig. 1). Zoals vrijwel alle graven had het een oriëntatie zuidoost-noordwest. Enkele tandkapsels maken duidelijk dat het hoofd in het zuiden lag. Aan het voeteneinde van het graf werd een knikwandpot uit de vroege middeleeuwen gevonden. In de buurt van het hoofd stond een klein potje van Romeins aardewerk. Naast dit potje lagen een gehalveerde Romeinse meloenkraal, een fragment Romeins glas en een fragment ijzer. Ter hoogte van de linkerheup zijn diverse metalen voorwerpen gevonden, zoals twee kleine riemtongen, een gespje, fragmenten van ijzeren ringen en een benen kam. De vondsten lagen zo dicht bij elkaar dat we ervan uit kunnen gaan dat ze in een tasje zaten. Tot slot moeten hier de kralen genoemd worden, het onderwerp van deze bijdrage: ca. 725 stuks in totaal (fig. 2, hieronder komt nog aan de orde waarom het exacte aantal (nog) niet kan worden bepaald). Vanwege deze kralen wordt aangenomen dat het om een vrouwengraf gaat. Voor het grootste gedeelte betreft het kleine monochrome gele kralen, tientallen anderskleurige monochrome blauwe, rode en groene kralen en 76 polychrome, soms zeer zeldzame kralen. Ze lagen in het zuidwestelijke deel van het graf, rond de nek of op de borst van de 
Fig. 1. SittardKemperkoul. Graf 11 op een uitsnede van de opgravingstekening uit 1984. Het noorden is onder (uit Kars et al. 2016).

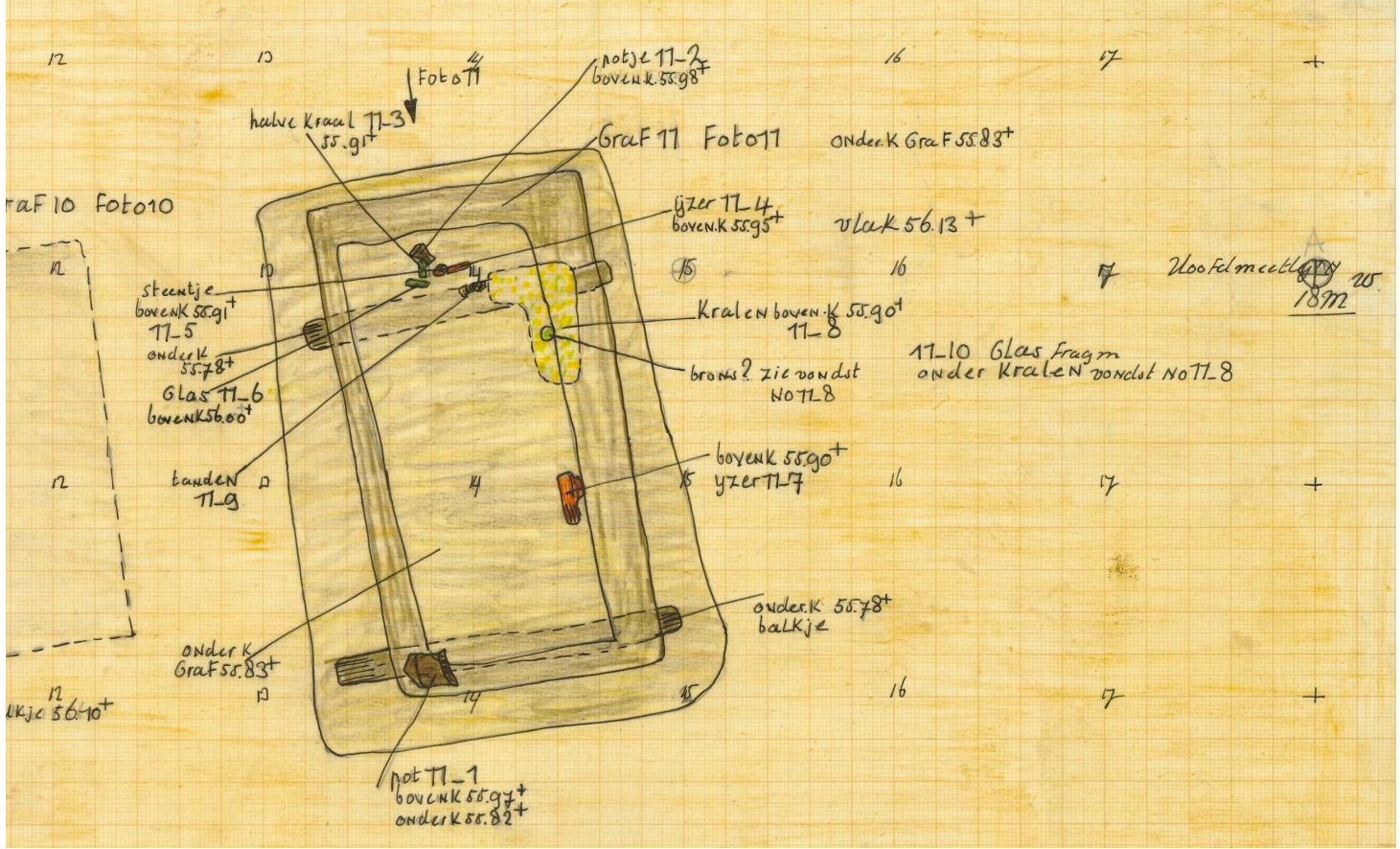

overledene. Waarom ze tijdens en na de opgraving verdeeld zijn over vier snoeren is onduidelijk. Onder de kralen lagen fragmenten van een glazen beker. Op basis van de vondsten is het graf te de dateren tussen ongeveer 560 en 650 n.Chr. (Kars et al. 2016).

De opname van de kralen in de nieuwe tentoonstelling bood de gelegenheid ze te onderzoeken met moderne, non-destructieve technieken. Er werd gebruik gemaakt van een combinatie van chemisch onderzoek met een handheld XRF en scans met een tafelmodel micro-CT-scanner.

\section{XRF}

Van de snoeren uit graf 11 werden honderden veelal kleine, monochrome gele kralen chemisch onderzocht met een handheld röntgenfluorescentiespectrometer (handheld XRF). Ter vergelijking werden ook enkele andere monochrome kralen geanalyseerd. Uit het onderzoek bleek dat sprake is van een hoog gehalte aan chloor. Dit toont aan dat de kralen na de opgraving behandeld zijn met
PVC, een conserveringsmiddel dat tegenwoordig niet meer wordt gebruikt. Tijdens de behandeling met PVC zijn waarschijnlijk veel kleine, enkelvoudige gele kralen 'verplakt' tot dubbele of driedubbele kralen. Een exacte telling van de kralen is daardoor niet mogelijk. Door de PVC konden niet alle elementen worden geanalyseerd met XRF, maar vooral de zwaardere elementen.

In het onderzoek ging de aandacht vooral uit naar de chemische variatie in een aantal sleutelelementen. Opaak geel glas werd namelijk in de regel gemaakt door aanzienlijke hoeveelheden lood en tin aan gesmolten glas toe te voegen. Zo ontstonden er gele lood-tin-oxide mineralen in het glas (Heck et al. 2003; Tite et al. 2008). De gele kralen van Sittard blijken inderdaad hoge gehaltes aan lood en tin te bevatten (fig. 3 links). Opvallend is echter dat binnen de kleine kraaltjes twee groepen zijn te onderscheiden, op grond van verschillen in de verhouding tussen lood en tin. De grote gele kralen vormen een klein derde groepje. Deze driedeling duidt erop dat sprake is 


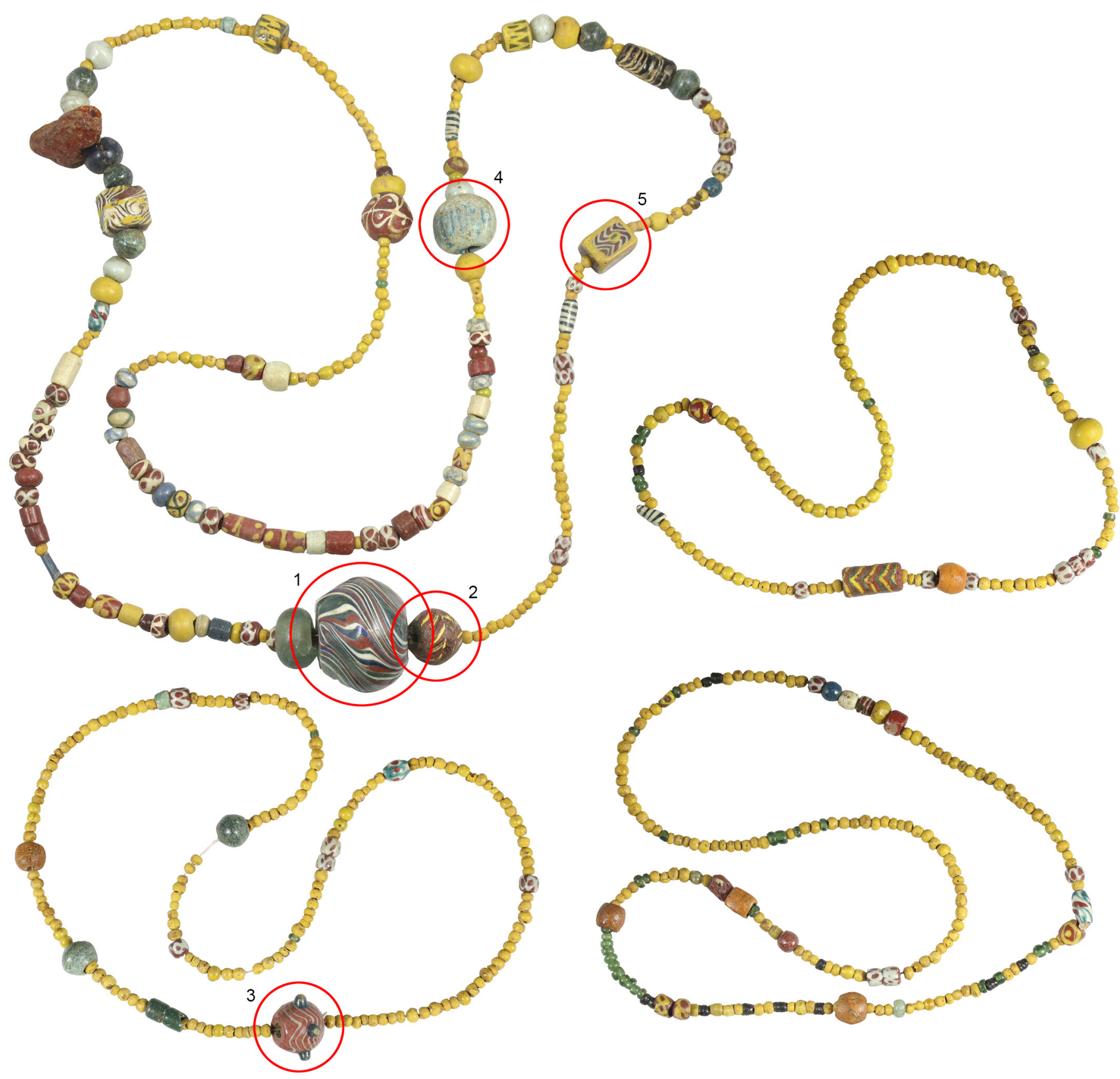

Fig. 2. Sittard-Kemperkoul. De vier kralensnoeren uit graf 11. De kralen die zijn geselecteerd voor micro-CT-scanning zijn aangegeven in rode cirkels. Schaal 1:2 (foto's Paulien Gemmeke). 

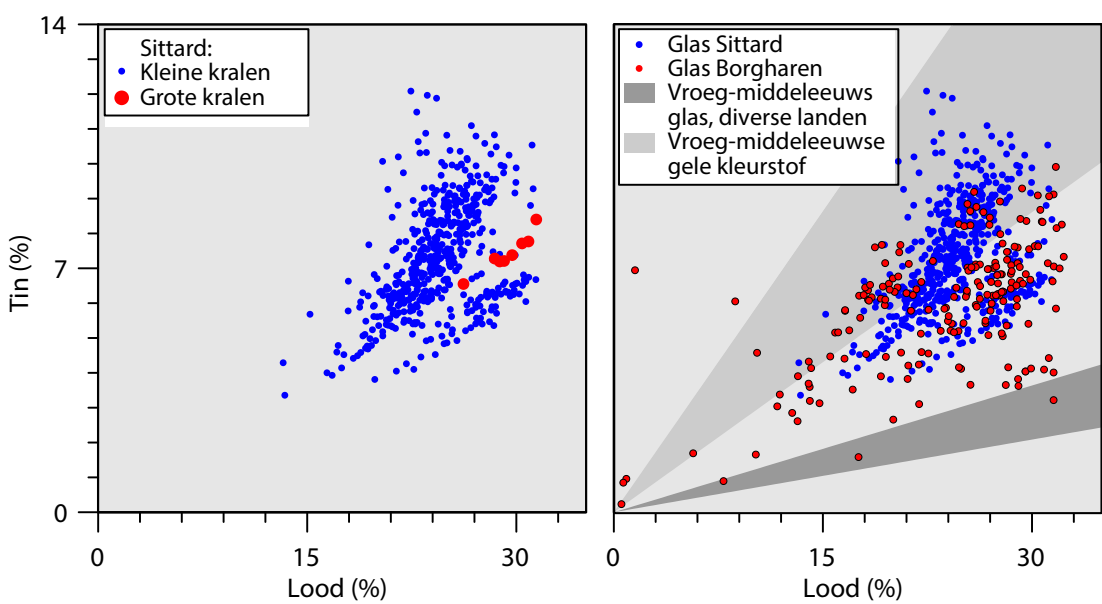

Fig. 3. Sittard-Kemperkoul en Borgharen. Links: de lood- en tingehaltes van de gele kralen uit graf 11. In de kleine kraaltjes zijn twee grote groepen te onderscheiden, terwijl de grotere gele kralen een derde groep vormen. Rechts: zoals links, maar met een vergelijking met de gele kralen van het Merovingische grafveld van Borgharen. De grijze banen op de achtergrond geven de verhoudingen tussen lood en tin aan in puur lood-tin geel (de kleurstof) en in geel Merovingisch glas van andere locaties. De kralen van Borgharen en Sittard lijken qua samenstelling vooral op de kleurstof, en wijken af van andere gele Merovingische kralen.

van het gebruik van verschillende, los van elkaar geproduceerde partijen geel glas. Die partijen kunnen bijvoorbeeld in één keer geproduceerd zijn, of ze komen uit verschillende werkplaatsen.

Het is interessant om een vergelijking te maken met soortgelijk onderzoek van kralen uit het Merovingische grafveld van Borgharen (Limburg; Lauwerier \& de Kort 2014). Ook hier werden verschillende groepen onderscheiden in de gele kralen. Het onderscheid tussen de groepen hield verband met de verdeling over de graven en met de vorm van de kralen. Als we de kralen van Sittard en Borgharen met elkaar vergelijken in één grafiek, valt op dat de groepen nauwelijks overlappen (fig. 3 rechts). Mogelijk vertegenwoordigen deze groepen verschillende productiepartijen of verschillende werkplaatsen.

De chemische analyse maakt ook duidelijk dat het gehalte aan calcium van de gele (en zwarte) kralen uit Sittard opvallend laag is (fig. 4 boven): veel lager dan de blauwe, rode en groene kralen in Sittard (fig. 4 midden), en veel lager dan de
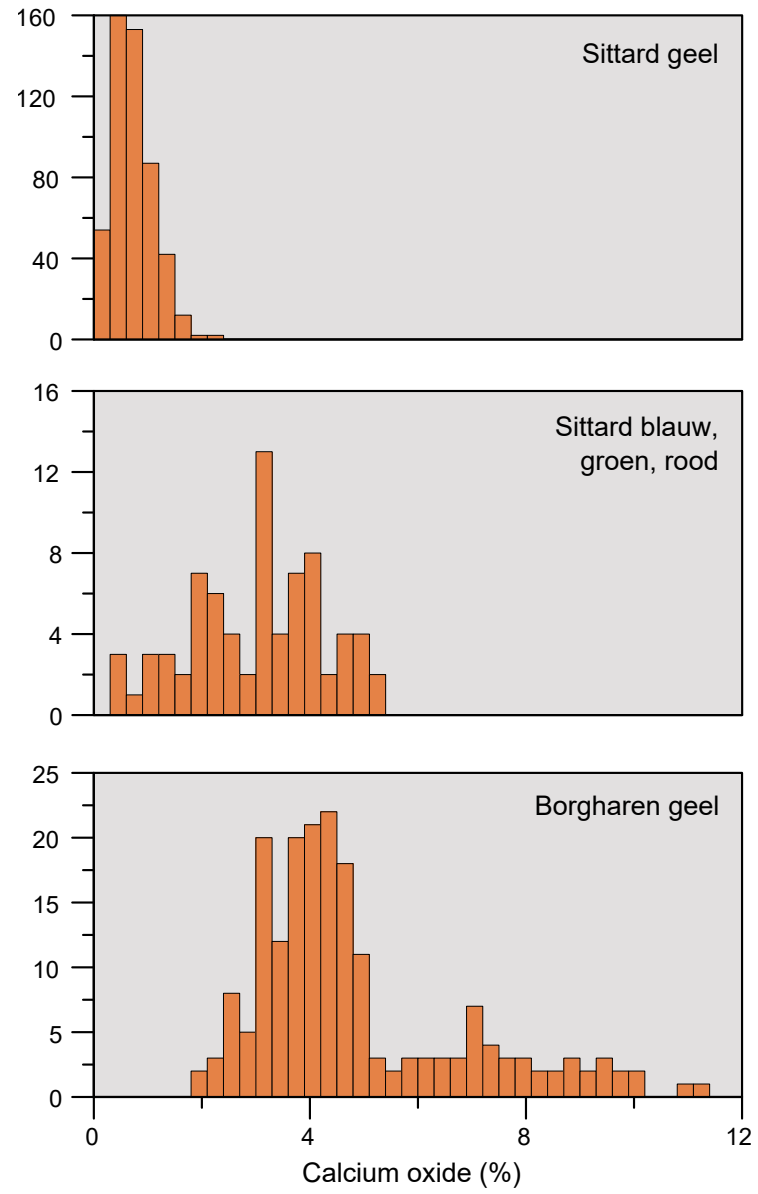

Fig. 4. De calciumgehaltes de kralen uit SittardKemperkoul en Borgharen. Boven: gele kralen; midden: blauwe, groen en rode kralen uit Sittard; onder gele kralen uit Borgharen (x-as: gehalte; y-as: aantallen kralen).

gele kralen van Borgharen (fig. 4 onder). In die kralen komt het calciumgehalte overeen met het op soda gebaseerde glas dat in de Romeinse tijd en vroege middeleeuwen in Europa werd gebruikt. Dit glas werd in grote hoeveelheden geproduceerd in het Midden-Oosten en vervolgens onder meer naar Europa getransporteerd. De gele kralen van Sittard lijken dus niet van sodaglas gemaakt te zijn, maar van een gesmolten mengsel van lood, tin en fijn of fijngemalen zand, de 
Fig. 6. Micro-CT-scanresultaten op de onderzochte kralen uit graf 11. A: Sittard-Kemperkoul. Graf 11. Doorsnede van kraal 5. De micro-CT-scan laat zien dat er twee kleine gele kraaltjes verstopt zitten in de kraal. B Luchtbellen rondom de schacht van deze rechthoekige kraal zijn vervormd toen de kraal rechthoekig werd gemaakt. C,D,E,F Verschillende doorsnedes van de gescande glazen kralen (respectievelijk 1, 2, 5 en 3) door verschillen wijzen van decoreren. $\mathrm{G}, \mathrm{H}$, I: Diverse scans van de grote kraal 1: (G) zijaanzicht van de schacht (blauw) met in geel-oranje de lichtgekleurde versiering op de buitenkant. De versiering beperkt zich tot het uiterste buitenste laagje; $(\mathrm{H})$ zijaanzicht van de schacht met alle luchtbellen. Ze vormen een heterogeen, wervelend patroon; (I) bovenaanzicht van de schacht, versiering en luchtbellen. De luchtbellen komen vooral voor waar de versiering ontbreekt. Waarschijnlijk zijn ze ontstaan bij het aanbrengen en vormen van de versiering. J, K: Scans van de Romeinse meloenkraal; bovenaanzicht $(J)$ en zijaanzicht van de holtes in de kraal (K). Er is een patroon van parellelle, langgerekte holtes te zien: mogelijk is hier plantaardig materiaal aanwezig geweest. L,M,N: Scans van kraal 2: (L) zijaanzicht. De lichte banden in de kraal zijn stroken geel en/of zwart glas; (M) driedimensionaal patroon van het gele en zwarte glas in de kraal. Ze vormen banden met spiraalpatronen. De versiering werd aangebracht door eerste dunne bandjes zwart en/of geel glas rond staafies te wikkelen en vervolgens de staafjes rond de kern te winden - de zg. reticella techniek; (N) bovenaanzicht van de bellen rondom de schacht. De kleine, afgeronde bellen zitten in de kern. De langgerekte bellen zijn ontstaan bij het winden van de staafjes rond de glaskern.
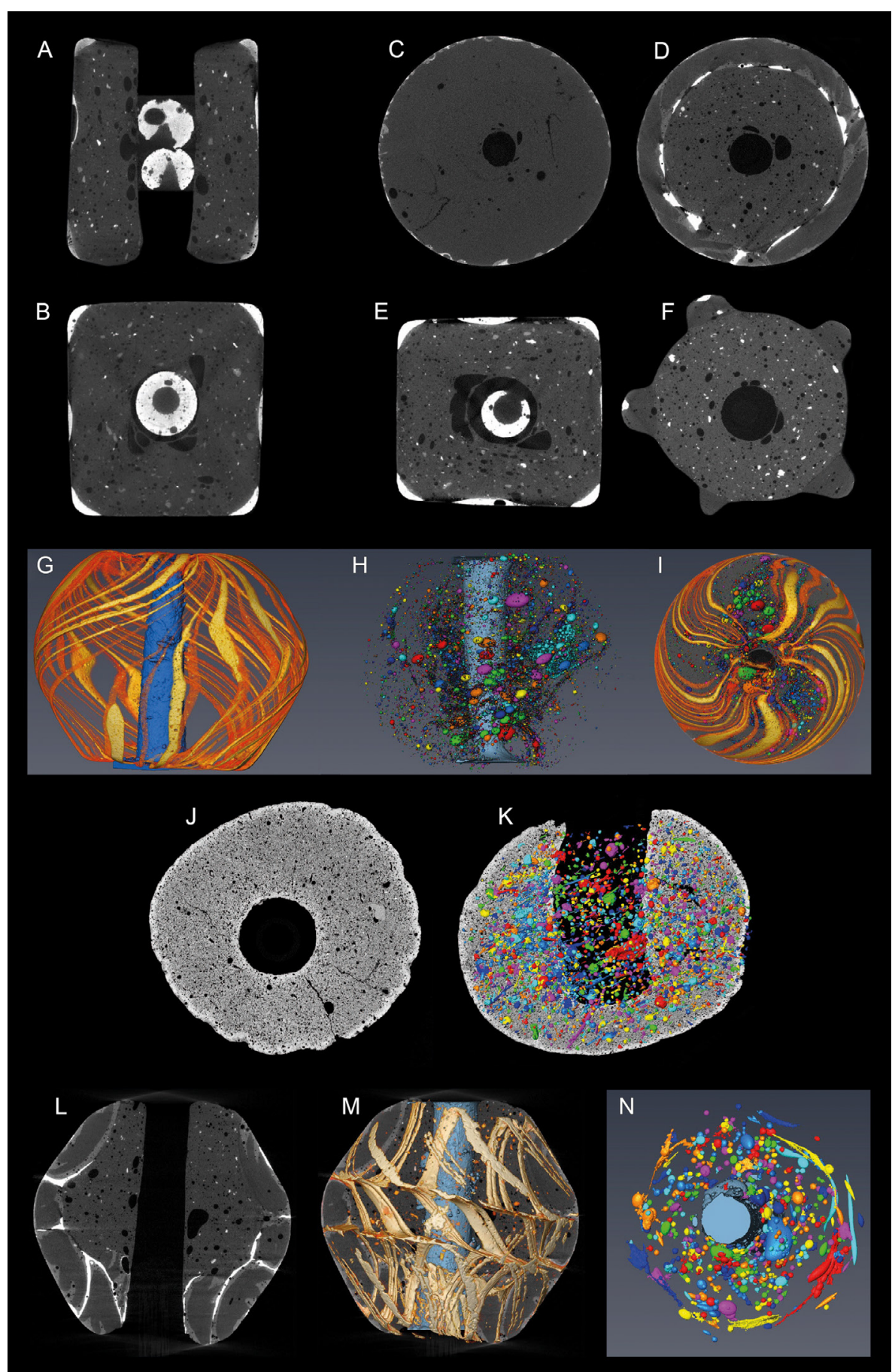
ronde, rode kraal met een verfijnde decoratie van regelmatig verdeelde dunne lijnen in zwart en geel; (3) een kraal met een decoratie van zeer dunne, parallel golvende witte lijnen op een rood oppervlak en vijf opvallende uitstekende delen; (4) een vermoedelijk Romeinse groene meloenkraal; en (5) een rechthoekige kraal versierd met gekleurde ribben, lijnen en oogjes. Op de linker pagina zijn in een reeks van afbeeldingen (fig. 6) doorsnedes en driedimensionale modellen van de oppervlaktes (binnen en buiten) van de kralen te zien. In sommige gevallen zijn de glaskleuren aangegeven. Bij het analyseren van de scans bleek dat in de schacht van de vierkante kraal twee kleine gele kralen aanwezig zijn (fig. 6a). Die kleine kralen zijn kennelijk in de grote kraal geschoven toen ze op hetzelfde snoer waren geregen; waarschijnlijk tijdens de opgraving, mogelijk al daarvoor.

De analyse van de scans leverde een goed beeld op van de wijze waarop de kralen gemaakt zijn. Vier van de vijf kralen zijn gemaakt door glas te vormen of te winden rondom een taps toelopende, metalen staaf. Dat blijkt uit de regelmatige, taps toelopende schachten (fig. 5) en de wervelende clusters luchtbellen. Dat geldt ook voor de twee kleine gele kraaltjes in de vierkante kraal (fig. 6a). Bij de vijf kralen zijn daarnaast ook grote luchtbellen aanwezig in de nabijheid van de schachten. Deze werden ingevangen tijdens het winden van het glas (fig. 5). Kraal 5 is na het winden en decoreren rechthoekig gemaakt door hem in gesmolten toestand aan alle zijden tegen een metalen plaat te drukken. Daarbij zijn de grote bellen naast de schacht vervormd tot een rechthoekige groep (fig. 6b).

De kernen van de kralen 2, 3 en 5 zijn gemaakt van vergelijkbaar, of misschien wel van hetzelfde glas: homogeen glas met een lage absorptie van röntgenstraling en met een groot aantal kleine en grote insluitsels (fig. 6c, d,e en f). De kern van kraal 1 is anders: die bevat geen insluitsels en de luchtbellen zijn ongelijk verdeeld, waarbij er delen van de kraal zijn - in de kern en aan de randen die zelfs helemaal vrij zijn van bellen (fig. $6 \mathrm{~g}, \mathrm{~h}$ en i). (Meloen)kraal 4 wijkt sterk af van de andere kralen. De schacht is krom en loopt niet taps toe (fig. 5, kraal no. 4). De structuur is heterogeen en poreus in vergelijking met gewoon, gesmolten glas (fig. 6j). Ook de grijswaarden zijn heel anders dan die in gangbare glaskralen. Het valt op dat de oppervlakte van deze kraal lichter van kleur en homogener is. Holtes zijn niet afgerond en grover en onregelmatiger van vorm. Sommige holtes zijn opvallend langgerekt en liggen parallel, maar met een oriëntatie die onafhankelijk is van de schacht of het oppervlak van de kraal (fig. 6k). Waarschijnlijk is deze kraal niet gemaakt van glas, maar van faience of frit: een materiaal dat in samenstelling veel lijkt op glas maar dat niet volledig is gesmolten. De binnenkant bestaat uit aan elkaar gesinterde korrels, terwijl alleen het massieve en dunne oppervlak van de kraal volledig is verglaasd. De kromme schacht is een aanwijzing dat de kraal eerst is gevormd en vervolgens verhit. Daarbij is de kraal enigszins in elkaar gezakt en is de schacht vervormd. De langgerekte holtes (fig. 6k) zouden afdrukken kunnen zijn van plantenresten die met de grondstoffen van de faience of frit gemengd waren. Faience en frit zijn hoofdzakelijk bekend uit het Midden-Oosten, waar het vooral werd toegepast in sieraden, wandversiering en kunstvoorwerpen.

De vier grote glazen kralen hebben allemaal meerkleurige decoraties op de buitenkant. Bij de kralen 1, 3 en 5 is een uit banden bestaande decoratie direct op het glaslichaam aangebracht. Deze decoraties werden gevormd door draden, strepen of druppels gekleurd glas op het oppervlak van het glas te leggen en ze daarin te laten wegzinken door ze langdurig te verhitten terwijl de kraal werd gedraaid. Bij de grote kraal werd de grove spiraalvorm waarschijnlijk bereikt door een metalen voorwerp door het gesmolten glas te trekken. Daarbij is vermoedelijk de onregelmatige verdeling van luchtbellen in deze kraal ontstaan (fig. 6g, h en i). Bij kraal 5 werden de rechthoekige omlijsting en de middenstippen aangebracht na het aanbrengen van de witte decoratie. De uitsteeksels van kraal 3 werden gemaakt door stukjes 
groen glas aan te brengen op de al bestaande, ronde rode vorm met witte golvende lijndecoratie. Deze fragmenten zakten vervolgens gedeeltelijk weg in de kern en kregen een afgeronde vorm. Vervolgens werden ze voorzien van een gele stip.

De scans laten zien dat het vervaardigen van kraal 2 ingewikkelder was (fig. 61, m en n). Eerst werden glasstaven gemaakt van rood glas. Die werden omwikkeld met dunne draden van zwart en geel glas, sommige met de klok mee en andere tegen de klok in. Stukken van deze staven werden vervolgens rond gebogen en parallel rondom de glazen kern aangebracht. Vervolgens werd dit geheel gevormd tot een min of meer ronde kraal. Drie banden omwikkelen de kern. Aan één kant ligt een vierde band rondom de schacht, maar die ontbreekt aan de andere kant. Daardoor is de kern aan de ene kant van de kraal niet zichtbaar van buitenaf, aan de andere kant wel. Waar de banden bij elkaar komen zijn langgerekte holtes ontstaan omdat de banden niet geheel op elkaar aansluiten. Deze techniek, waarbij een visgraatpatroon ontstaat op de buitenkant van de kraal, staat bekend als reticella.

\section{Conclusie}

Het is opvallend hoe verschillend de kralen uit één graf kunnen zijn. De eenvoudige monochrome kralen blijken op twee verschillende manieren gemaakt te zijn: een deel op basis van geïmporteerd of hergebruikt Romeins sodaglas, een ander deel van een mengsel van metalen en fijne kwarts. Waar de grondstoffen ook vandaan komen, de vervaardiging van de kralen kan in de nabijheid van Sittard plaats hebben gevonden, bijvoorbeeld in de werkplaats die is opgegraven in Maastricht (Sablerolles et al. 1997). Er zijn in Nederland geen vroegmiddeleeuwse werkplaatsen bekend waar meerkleurige kralen gemaakt werden. De grote kralen uit het graf van Sittard zijn waarschijnlijk geïmporteerd uit verschillende buitenlandse werkplaatsen, bijvoorbeeld in Zuid-Europa. Daarbij moet worden opgemerkt dat het niveau van vakmanschap bij sommige van deze polychrome kralen opvallend hoog ligt. De meloenkraal is een bijzonder geval: het gaat hier vrijwel zeker om een hergebruikte Romeinse kraal. Dat is niet vreemd gelet op de andere Romeinse voorwerpen die in dit graf gevonden zijn.

De vrouw die werd begraven in graf 11 van Sittard-Kemperkoul kreeg een zeer uitgebreide set aan grafgiften mee. Vooral de variëteit in vorm, herkomst en ouderdom van de meegegeven kralen laten zien dat deze vrouw en haar naasten toegang hadden tot uitgebreide bovenregionale netwerken van goederenuitwisseling (Langbroek 2018). De grafgiften met een Romeinse ouderdom maken duidelijk dat bewust een relatie werd gelegd met het verleden. Of deze objecten via gelijksoortige bovenregionale uitwisselingsnetwerken werden verkregen is niet te zeggen; verschillende acquisitiescenario's zijn mogelijk (Kars 2011: 71-74; Mehling 1998). Hoe dan ook, de vondsten uit graf 11 laten zien dat de gemeenschap die van het grafveld van Sittard gebruik maakte niet geïsoleerd leefde, maar relaties had met gemeenschappen in Merovingisch Europa die ver buiten de huidige regio Limburg lagen.

\section{Making and trading: An analysis} of Merovingian beads from the Sittard-Kemperkoul burial ground Chemical analyses and micro-CT scanning were used to analyse a set of c. 725 glass beads from a single Merovingian burial (number 11) in the Sittard-Kemperkoul burial ground (SittardGeleen, province of Limburg). Chemical analyses of the small, opaque, yellow beads that make up the majority of the collection showed that they were, in fact, not made of glass. Rather, they were made by fusing a lead-tin-based yellow colourant with quartz. For black beads, iron was added to this mixture. The other beads were made from glass - probably of re-used Roman origin - with various colourants. The micro-CT scans provided an unrivalled image of the various manufacturing techniques that were used to make the more complex, polychrome beads. 


\section{Noten}

1. Rijksdienst voor het Cultureel Erfgoed, Smallepad 5, 3811 MG Amersfoort.

2. Groninger Instituut voor Archeologie, Poststaat 6, 9712 ER Groningen.

3. Gemeente Sittard-Geleen.

4. Vrije Universiteit/Portable Antiquities of the Netherlands, De Boelelaan 1105, 1081 HV Amsterdam.

5. Faculteit Civiele Techniek en Aardwetenschappen, TU Delft, Stevinweg 1, 2628 CN Delft.

\section{Literatuur}

Heck, M., Th. Rehren \& P. Hoffman, 2003. The production of lead-tin yellow at Merovingian Schleitheim (Switzerland). Archaeometry 45, 33-44.

Kars, M., 2011. A cultural perspective on Merovingian burial chronology and the grave goods from the Vrijthof and Pandhof cemeteries in Maastricht, Amsterdam.

Kars, M., F. Theuws \& M. de Haas, 2016. The Merovingian cemeteries of Sittard-Kemperkoul, Obbicht-Oude Molen and Stein-Groote Bongerd, Bonn (Merovingian Archaeology in the Low Countries 3).

Langbroek, M., 2018. Wereld van kralen. Omzwervingen van barnsteen in de Merovingische periode. Madoc. Tijdschrift voor de Middeleeuwen 32, 140-150.
Lauwerier, R.C.G.M. \& J.W. de Kort (red.), 2014. Merovingers in een villa 2. Romeinse villa en Merovingisch grafveld Borgharen - Pasestraat Onderzoek 2012 (Rapportage Archeologische Monumentenzorg 222), Amersfoort, Rijksdienst voor het Cultureel Erfgoed.

Mehling, A., 1998. Archaika als Grabbeigaben. Studien an merowingerzeitlichen Gräberfeldern, Rahden.

Ngan-Tillard, D.J.M., D.J. Huisman, F. Corbella \& A. Van Nass, 2018. Over the rainbow? MicroCT scanning to non-destructively study Roman and early medieval glass bead manufacture. Journal of Archaeological Science 98, 7-21.

Sablerolles, Y., J. Henderson, \& W. Dijksman, 1997. Early Medieval Glass Bead Making in Maastricht (Jodenstraat 30), The Netherlands. An Archaeological and Scientific Investigation, In: U. von Freeden \& A. Wieczorek (red.), Perlen: Archäologie, Techniken, Analysen, Kolloquien zur Vor- und Frühgeschichte 1, 291-213.

Tite, M., T. Pradell \& A. Shortland, 2008. Discovery, production and use of tin-based opacifiers in glasses, enamels and glazes from the Late Iron Age onwards: a reassessment. Archaeometry 50, 67-84.

Zoetbrood, P.A.M., 1984. Een Merovingisch grafveld te Sittard (ongepubliceerde masterscriptie Universiteit van Amsterdam). 